\title{
Article \\ Key Criteria in the Choice of IoT Platforms in Spanish Companies
}

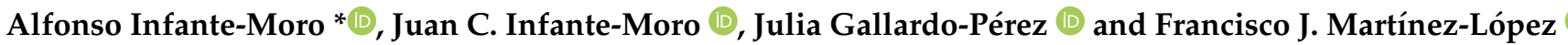 \\ Department of Financial Economics, Accounting and Operations Management, University of Huelva, \\ 21071 Huelva, Spain; juancarlos.infante@decd.uhu.es (J.C.I.-M.); julia.gallardo@decd.uhu.es (J.G.-P.); \\ francis@uhu.es (F.J.M.-L.) \\ * Correspondence: alfonso.infante@decd.uhu.es
}

check for updates

Citation: Infante-Moro, A.;

Infante-Moro, J.C.; Gallardo-Pérez, J.; Martínez-López, F.J. Key Criteria in the Choice of IoT Platforms in Spanish Companies. Appl. Sci. 2021, 11, 10456. https://doi.org/ 10.3390/app112110456

Academic Editor: Eui-Nam Huh

Received: 26 September 2021

Accepted: 4 November 2021

Published: 7 November 2021

Publisher's Note: MDPI stays neutral with regard to jurisdictional claims in published maps and institutional affiliations.

Copyright: (c) 2021 by the authors. Licensee MDPI, Basel, Switzerland. This article is an open access article distributed under the terms and conditions of the Creative Commons Attribution (CC BY) license (https:/ / creativecommons.org/licenses/by/ $4.0 /)$.

\begin{abstract}
The level of implementation of IoT technology in Spanish companies is not low for a novel technology, but there are concerns that hinder its level of implementation from being higher: initial costs, security, and privacy. These concerns could be solved with the choice of the appropriate IoT platform, but it must be taken into account that there are numerous criteria that participate in this decision that influence each other. This could give rise to criteria not being considered at first, even though they should be taken into account in this choice. Existing studies do not consider this. Thus, the objective of this study was to find out what are the key criteria to be taken into account by Spanish companies when choosing an IoT platform. The criteria were located through a literary review, and classified according to their level of importance in this decision through a causal study carried out with the methodology of fuzzy cognitive maps. The results achieved showed that there were key criteria beyond the criteria directly implied by the concerns, such as stability, scalability, flexibility, and interoperability, and these new criteria acquired the same or greater importance.
\end{abstract}

Keywords: IoT platforms; Spanish companies; decision making; key criteria; ICT

\section{Introduction}

The Internet of Things (IoT) is expected to revolutionize the business sector as it develops as a technology (providing new solutions) and as companies bet on its implementation. It is said that the revolution of the arrival of the IoT to companies is and will be similar to the revolution caused by the arrival of computers in that sector, as its arrival will change the way in which companies do business, since it will create new ways of communication between companies with customers, and increase companies' productivity and efficiency [1-6].

The IoT is a technology that allows the interconnection between devices in order to collect, transmit, and store data. Its value in the business sector goes beyond the sensors and devices by which most users know this technology; its true value arises from the data it collects and the use of that data through different applications [7].

For companies, this technology can have the following advantages [8-11]:

- $\quad$ Savings in energy consumption, thanks to intelligent infrastructures and their sensors.

- A reduction in costs, since it can predict failures in machinery and production lines, eliminating downtime caused by these failures, thanks to the possibility of monitoring these machines and production lines.

- $\quad$ Greater production efficiency, since it allows evaluation of demand in real time.

- $\quad$ Better use of changing markets, since it allows improvements in strategies thanks to the collected data to be marked.

- $\quad$ A greater understanding of customers, in terms of their behavior. The collected data make it possible to identify preferences and trends among customers, which can help companies to provide more personalized services and products to their customers and detect business opportunities. 
- Better service to customers, facilitating transactions and monitoring their purchases.

- Greater security for employees, including both physical and property, due to the monitoring of the companies' workplaces, which allows them to receive notifications of any security risks.

- Greater security and privacy of company information: IoT technology allows employees' personal devices to be configured; thus, when consulting information from their devices, employees' security and privacy is not compromised.

- Better decision making and strategy planning, thanks to the data collected by the interconnected devices.

The increase in the use of IoT in society is quite visible globally, and 2021 is expected to be the year with the highest growth compared to the previous year (with an increase of $68.5 \%$ ) and the year with the highest spending on this type of technology (in the years 2019-2022, an increase in spending of $34.23 \%$ is expected compared to 2018, reaching one trillion US dollars) [12].

Within the European Union, Spain has the fifth largest IoT market share (6\% in 2020), which means that $16.8 \%$ of Spanish companies have used interconnected devices that can be remotely monitored or controlled through IoT in 2020 [13]. The level of implementation of this technology in Spanish companies is not low for a novel technology, but there are concerns that hinder its level of implementation from being higher.

Spanish companies that implement this technology do so by automating processes in $26 \%$ of cases, by reducing operation costs in $24 \%$ of cases, and by improving the customer experience in $23 \%$ of cases. Among the difficulties in betting on its implementation, companies cite initial costs in $29 \%$ of cases, security concerns in $25 \%$ of cases, and privacy problems in $17 \%$ of cases [12].

These difficulties could be solved with the choice of an appropriate IoT platform, which makes such a choice important when deciding on the use of IoT in companies, since these platforms are necessary for the implementation of the IoT including receiving, connecting, storing, and analyzing data. IoT platforms are the software that allows connection of devices, sensors, actuators, and industrial equipment in a digital environment, creating a network where these elements can communicate and generate valuable information for companies [14].

The number of platforms is constantly growing: in 2015, there were 260 platforms; in 2017, there were 450; and in 2019, there were 620 [15]. This causes the choice of the IoT platform to become a complicated process, where the decision to opt for one or the other is based on a series of criteria or factors to be taken into account.

Therefore, if we want to increase the level of implementation of this technology in Spanish companies and promote the best possible choice of an appropriate IoT platform, it is not only necessary to take into account the criteria based on the most often cited difficulties, since there are numerous other criteria involved in this decision, and the influences between them must be taken into account. This could give rise to criteria not being considered at first, even though they should be taken into account in this choice. Existing studies do not consider this.

Hence, the objective of this study was to identify the key criteria to be taken into account by Spanish companies when choosing an IoT platform. The criteria were located through a literary review of the main international scientific databases, and classified according to their level of importance in this decision through a causal study carried out with the methodology of fuzzy cognitive maps.

This will facilitate the selection process for future Spanish companies that want to implement IoT technology, as they will have a clear picture of the most important criteria to take into account when opting for one or another platform in this country. This will also encourage other companies that did not plan to implement this technology due to finding this process too difficult to implement IoT technology.

Furthermore, this study may increase the number of Spanish companies using IoT and help reduce the existing gap with respect to the country with the largest IoT market share 
in Europe (United Kingdom, with a 23\% market share in 2020) [12], which would obviously translate into an up-to-date and powerful business sector in terms of technologies, which reaches a global benchmark.

\section{Literature Review}

As mentioned in the introduction, this literary review focused on locating the criteria to be taken into account by Spanish companies when choosing an IoT platform; these are criteria with worldwide relevance. For this, criteria were for searched among the studies that are deposited in the main international scientific databases, such as Web of Science, Scopus, and Google Scholar. Following this search, it was decided to opt for the selection of criteria detailed in the study by Ullah, Nardelli, Wolff, and Smolander [16], where through the Delphi method and using the knowledge of experts in this field as a source, 21 criteria that influence this decision of companies to choose an IoT platform were detected. These criteria are described below, and their participation in this decision was also confirmed in other research studies that are cited for each of these criteria:

Scalability: Capacity to guarantee the technology's functions as the company and its businesses grow [17].

Flexibility: Capacity to adapt according to technological advances [17].

Data Analytics and Visualization Tools: Capacity to integrate data analytics and visualization tools [18].

Redundancy and Disaster Recovery: Capacity to handle data during problems in the technological infrastructure [19].

Stability: Capacity of the provider to last in the market and not disappear [17].

Security: Capacity to offer a secure service: device-to-cloud network security, data encryption, application authentication, secure session initiation, application authentication, cloud security, and device security (authentication and up-to-date certification) [20].

Data Ownership: Data rights and the territorial scope of data protection based on the laws of the jurisdiction to which the provider belongs, since the regulations on data ownership are different depending on the jurisdiction of the provider [21].

Protocol: Capacity to support new protocols and ease of updating protocols. Among these protocols are MQTT, HTTP, AMQP, and CoAP, highlighting MQTT for its low weight and low overhead $[19,22]$.

System Performance: System performance based on the number of devices that are connected [23].

Time to Market: Installation time and support in this process from the supplier [20]. Some platforms offer quick start packages.

Extent of Legacy Architecture: Capacity to interconnect with new and old company technologies [24-26].

Attractive Interface: Simple, attractive, and easy-to-use interface.

Pricing Model and Business Case: Capacity to offer complete functions at a constant and reasonable price for the budget of the company, since there are platforms that offer low prices at the beginning and then make it more expensive, and platforms that offer low prices but limit their functions $[17,27]$.

Ownership of Cloud Infrastructure: Compatibility of the IoT platform provider with public cloud providers. The hardware infrastructure layer is expensive, and some platform providers only offer the software layer, offering the hardware layer through public cloud providers [28].

Interoperability: Capacity to support integration with open-source ecosystems. The data collected can be used by many applications; some are provided by the platform and others are not, which is why interoperability is necessary [29-32].

Application Environment: Out-of-the-box applications, application development environment features, and common interfaces [28]. 
Hybrid Cloud: Capacity to adapt to existing technological systems hosted on company premises. This makes it possible for the most critical processes for the business to be carried out locally, while other processes are carried out through the platform [19,33,34].

Platform Migration: Capacity to provide the necessary tools for any possible migration to other IoT platforms $[17,19]$.

Previous Experience: Previous experience of the supplier in similar jobs to those required by the company, within the same scope [20].

Edge Intelligence and Control: Capacity of the IoT platform to support new topologies and use edge intelligence [35], as the future of these platforms is moving towards distributed, offline, and edge intelligence [36], and decisions need to be made based on local data (in addition to cloud data).

Bandwidth: Capacity to provide high bandwidth, since the transmission of information between the processing components requires efficient high bandwidth communication $[19,37]$.

\section{Objectives and Hypothesis}

After this analysis, it is necessary to emphasize again that the main objective of this research is to know what the key criteria are to be taken into account by Spanish companies when choosing an IoT platform. This will facilitate this selection process for future Spanish companies that want to implement this technology and may encourage other companies that did not have this technology among their plans to adopt it.

For this purpose, we formulated the following hypotheses that must be ratified or rectified in the course of this study:

Hypothesis 1. The difficulties or concerns that Spanish companies encounter when betting on the implementation of the IoT are not the only criteria to take into account when choosing an IoT platform.

Hypothesis 2. The difficulties or concerns that Spanish companies encounter when betting on the implementation of the IoT are not the most relevant criteria or key criteria in the choice of IoT platforms, since there are other criteria to take into account when choosing IoT platforms with equal or greater importance.

\section{Methodology}

Thus, the next steps in this study were to confirm whether all the criteria found in the literary review should be taken into account in the choice of the IoT platform and to classify these criteria according to their level of importance in this decision.

These steps were focused on Spanish companies, and made it possible to identify the key criteria in the choice of IoT platforms in Spanish companies thanks to the methodology of the fuzzy cognitive maps. According to each country, companies will have different concerns or difficulties when implementing this technology (depending on the countries' technological, regulatory, and/or economic level); thus, companies in each country will have different key criteria.

The methodology of fuzzy cognitive maps is a methodology used to identify causeeffect relationships between the elements involved in decision making [38-40]; it is based on the judgment of experts (it uses expert knowledge, obtained through interviews, as a source of information for the detection of cause-effect relationships between the elements involved in decision making, and as a source of information for the assessment of these cause-effect relationships based on the degree of influence that each element involved exerts on the other elements) [41] and allows (with the use of the appropriate software) to classify these elements according to their level of importance in the decision making, basing their level of importance on the degree of influence exercised and received by each elements involved in the decision making [42]. 


\subsection{Process}

In each interview, each expert confirmed whether the criteria detected in the literary review were all the criteria involved in the choice of an IoT platform by Spanish companies, and indicated whether any criteria had to be eliminated and/or added. For this, as observed in other studies that used this same methodology [43], each expert received a table with these criteria and their definitions (these definitions can also be seen in the section "literature review" above).

In addition, each expert had to assess the level of influence existing between the criteria involved in this choice (i.e., the cause-effect relationships) with an assessment comprised of values within the interval $[-1,1]$ : considering the value of -1 when a criterion exerts a strong negative influence on another criterion, considering the value of 0 when a criterion does not exert influence on another criterion, and considering the value of 1 when a criterion exerts a strong positive influence on another criterion [44,45].

Thus, an adjacency matrix (such as the one shown in Table 1) was filled in for each expert; each criterion involved received a row and column in the matrix.

Table 1. Global adjacency matrix.

\begin{tabular}{|c|c|c|c|c|c|c|c|c|c|c|c|c|c|c|c|c|c|c|c|c|c|}
\hline & 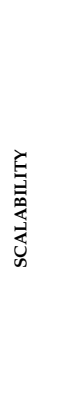 & 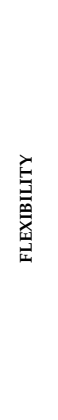 & 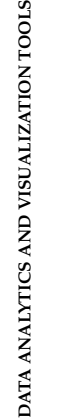 & 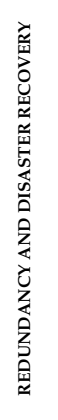 & 焉 & 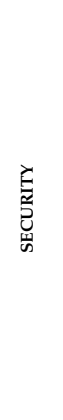 & 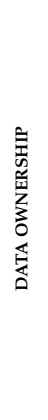 & 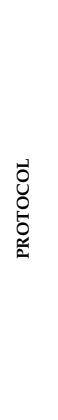 & 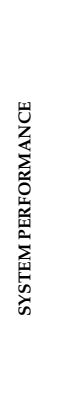 & 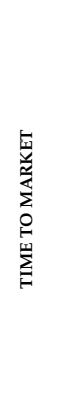 & 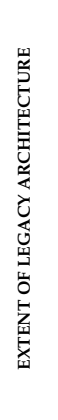 & 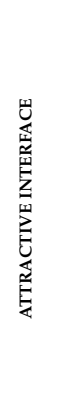 & 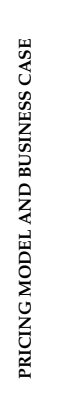 & 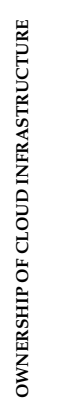 & 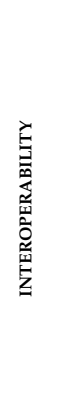 & 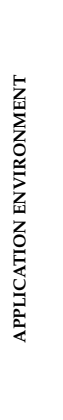 & 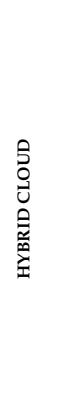 & 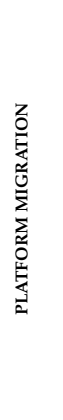 & 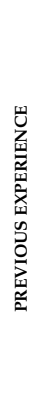 & 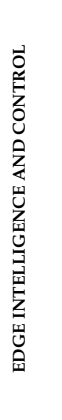 & 志 \\
\hline SCALABILITY & & 1.00 & 0.90 & 0.00 & 0.70 & 0.60 & 0.00 & 0.20 & 0.80 & 0.00 & 0.80 & 0.20 & -0.80 & 0.70 & 0.80 & 0.90 & 0.90 & 0.00 & 0.00 & 0.60 & 0.60 \\
\hline FLEXIBILITY & 1.00 & & 1.00 & 0.40 & 1.00 & 0.80 & 0.00 & 1.00 & 0.60 & 0.00 & 1.00 & 0.00 & 0.00 & 1.00 & 1.00 & 0.90 & 1.00 & 0.00 & 0.00 & 1.00 & 0.00 \\
\hline $\begin{array}{c}\text { DATA ANALYTICS } \\
\text { AND } \\
\text { VISUALIZATION } \\
\text { TOOLS }\end{array}$ & 1.00 & 1.00 & & 0.70 & 1.00 & 0.00 & 0.00 & 0.00 & 0.90 & -0.60 & 0.00 & 0.40 & -0.60 & 0.00 & 1.00 & -0.60 & 0.60 & 0.00 & 0.00 & 1.00 & 0.00 \\
\hline $\begin{array}{l}\text { REDUNDANCY } \\
\text { AND DISASTER } \\
\text { RECOVERY }\end{array}$ & 1.00 & 0.90 & 0.60 & & 1.00 & 1.00 & 0.00 & 0.00 & 0.90 & 0.00 & 0.60 & 0.00 & -0.40 & 0.00 & 0.60 & 0.00 & 0.70 & 0.00 & 0.00 & 0.70 & 0.00 \\
\hline STABILITY & 1.00 & 0.80 & 0.80 & 0.90 & & 1.00 & 0.00 & 0.75 & 0.70 & 0.00 & 0.60 & 0.70 & -0.60 & 0.70 & 0.70 & 0.60 & 0.70 & 0.00 & 0.00 & 0.70 & 0.60 \\
\hline SECURITY & 1.00 & 0.70 & 0.70 & 1.00 & 1.00 & & 0.00 & 0.70 & 0.60 & -0.40 & 0.70 & 0.00 & -0.60 & 0.80 & 0.80 & 0.20 & 0.80 & 0.60 & 0.00 & 0.70 & 0.00 \\
\hline DATA OWNERSHIP & 1.00 & 0.80 & 0.70 & 0.80 & 0.90 & 1.00 & & 0.80 & 0.00 & -0.80 & 0.80 & 0.00 & -0.60 & 0.80 & 0.00 & 0.80 & 0.00 & 0.90 & 0.00 & 0.80 & 0.00 \\
\hline PROTOCOL & 1.00 & 1.00 & 0.80 & 0.70 & 1.00 & 0.90 & 0.00 & & 0.90 & 0.00 & 0.80 & 0.00 & -0.60 & 0.90 & 0.80 & 0.80 & 0.80 & 0.00 & 0.00 & 0.80 & 0.00 \\
\hline $\begin{array}{c}\text { SYSTEM } \\
\text { PERFORMANCE }\end{array}$ & 1.00 & 0.00 & 0.50 & 0.90 & 1.00 & 0.80 & 0.00 & 0.40 & & -0.70 & 0.60 & 0.00 & -0.70 & 0.60 & 0.40 & 0.60 & 0.70 & 0.00 & 0.00 & 0.60 & 0.00 \\
\hline TIME TO MARKET & 0.00 & 0.00 & 0.00 & 0.00 & 0.40 & 0.00 & 0.00 & 0.00 & 0.00 & & 0.00 & 0.00 & -0.60 & 0.00 & 0.00 & 0.00 & 0.00 & 0.00 & 0.00 & 0.00 & 0.00 \\
\hline $\begin{array}{c}\text { EXTENT OF } \\
\text { LEGACY } \\
\text { ARCHITECTURE }\end{array}$ & 1.00 & 0.90 & 0.90 & 0.00 & 1.00 & -0.60 & 0.00 & 0.00 & 0.00 & -0.80 & & 0.00 & -0.60 & 0.00 & 0.90 & 0.00 & 0.00 & 0.00 & 0.00 & 0.00 & 0.00 \\
\hline $\begin{array}{l}\text { ATTRACTIVE } \\
\text { INTERFACE }\end{array}$ & 0.80 & 0.00 & 0.00 & 0.40 & 0.80 & 0.00 & 0.00 & 0.00 & 0.00 & 0.80 & 0.00 & & -0.40 & 0.00 & 0.00 & 0.00 & 0.00 & 0.60 & 0.00 & 0.00 & 0.00 \\
\hline $\begin{array}{l}\text { PRICING MODEL } \\
\text { AND BUSINESS } \\
\text { CASE }\end{array}$ & 1.00 & -0.60 & -0.60 & -0.80 & 1.00 & -0.60 & 0.00 & -0.60 & -0.60 & -0.60 & -0.70 & -0.50 & & -0.60 & -0.60 & -0.55 & -0.60 & -0.50 & 0.00 & -0.60 & -0.80 \\
\hline $\begin{array}{l}\text { OWNERSHIP OF } \\
\text { CLOUD } \\
\text { INFRASTRUCTURE }\end{array}$ & 0.80 & 0.80 & 0.00 & 0.75 & 0.00 & -0.80 & 0.00 & 0.00 & 0.00 & -0.60 & 0.00 & -0.30 & -0.40 & & 0.00 & -0.40 & 0.80 & 0.00 & 0.00 & 0.00 & 0.00 \\
\hline INTEROPERABILITY & 1.00 & 1.00 & 1.00 & 0.60 & 1.00 & -0.90 & 0.00 & 0.90 & 0.00 & -0.50 & 1.00 & -0.40 & -0.60 & 0.50 & 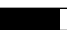 & -0.60 & 0.80 & 0.00 & 0.00 & 0.90 & 0.00 \\
\hline $\begin{array}{l}\text { APPLICATION } \\
\text { ENVIRONMENT }\end{array}$ & 1.00 & 1.00 & 0.60 & 0.60 & 1.00 & 1.00 & 0.00 & 0.00 & 0.00 & 0.90 & 0.00 & 0.80 & 0.80 & 0.00 & -0.65 & & 0.00 & 0.00 & 0.00 & 0.40 & 0.00 \\
\hline HYBRID CLOUD & 1.00 & 0.00 & 0.00 & 0.90 & 1.00 & -0.80 & 0.00 & 0.00 & 0.70 & -0.60 & 0.80 & -0.30 & -0.40 & 1.00 & 0.90 & -0.60 & 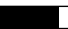 & 0.00 & 0.00 & 0.00 & 0.00 \\
\hline $\begin{array}{l}\text { PLATFORM } \\
\text { MIGRATION }\end{array}$ & -1.00 & 0.00 & 0.00 & 0.00 & -1.00 & 0.00 & 0.00 & 0.00 & 0.00 & 0.00 & 0.00 & 0.60 & 0.00 & 0.00 & 0.00 & -0.60 & 0.00 & & 0.00 & 0.00 & 0.00 \\
\hline $\begin{array}{c}\text { PREVIOUS } \\
\text { EXPERIENCE }\end{array}$ & 1.00 & 1.00 & 1.00 & 1.00 & 1.00 & 1.00 & 1.00 & 1.00 & 1.00 & 1.00 & 1.00 & 1.00 & 1.00 & 1.00 & 1.00 & 1.00 & 1.00 & 0.00 & & 1.00 & 0.00 \\
\hline $\begin{array}{c}\text { EDGE } \\
\text { INTELLIGENCE } \\
\text { AND CONTROL }\end{array}$ & 1.00 & 0.20 & 0.00 & 1.00 & 1.00 & -0.80 & 0.00 & 0.00 & 0.80 & -0.60 & 1.00 & -0.60 & -0.60 & 1.00 & 0.00 & -0.55 & 1.00 & 0.00 & 0.00 & & 0.00 \\
\hline BANDWIDTH & 1.00 & 0.00 & 0.00 & 0.00 & 1.00 & 0.80 & 0.00 & 0.00 & 1.00 & 0.00 & 0.00 & 0.00 & -0.60 & 0.00 & 0.00 & 0.00 & 0.00 & 0.00 & 0.00 & 0.00 & \\
\hline
\end{tabular}

This adjacency matrix had to be filled in with the evaluations provided by each of the interviewees regarding the influences that each criterion in the rows exerted on each of the criteria in the columns. For example, based on what can be seen in Table 1, the first row had to be filled in with the evaluations provided by each of the interviewees regarding the influences exerted by the scalability criterion on each of the criteria of the columns: scalability, flexibility, data analytics and visualization tools, redundancy and 
disaster recovery, stability, security, data ownership, protocol, system performance, time to market, extent of legacy architecture, attractive interface, pricing model and business case, ownership of cloud infrastructure, interoperability, application environment, hybrid cloud, platform migration, previous experience, edge intelligence and control, and bandwidth. The same had to be done with the other criteria that appear in the other rows.

It should be borne in mind that the level of influence that a criterion exerts on another criterion does not have to be the same level of influence that it receives from that criterion. It is even possible to find a criterion that influences another criterion but is not influenced by that criterion, and vice versa.

In this case, criteria were not eliminated from those provided in the literary review, since the experts believed that all of the criteria presented were involved in this decision making, and no new criteria were added by the experts. Therefore, the adjacency matrix to be filled in by each of the experts was the one found in Table 1.

Once an adjacency matrix was obtained by each of the experts, a global adjacency matrix had to be obtained (which was formed by the average evaluations of these experts). This global adjacency matrix was introduced to the FCMappers software, which analyzed these assessments and classified the criteria according to their level of importance in the choice of an IoT platform by companies, basing their level of importance on the degree of influence exerted and received among the criteria involved in this choice [46].

FCMappers was first released as a beta version in early July 2009, and is the first fuzzy cognitive map analysis tool available based on Microsoft Excel. For its operation, only the global adjacency matrix achieved with the use of the fuzzy cognitive maps methodology must be entered, and later this software automatically classifies the criteria by the degree of influence they exert on each other, by the degree of influences they receive from the other criteria, and by the degree of participation or influence in decision making.

\subsection{Participants}

The choice of experts is key in studies that use this type of methodology to add significance to the results achieved [47], and thus in this study, two different profiles were chosen:

- $\quad$ Researchers in technological implementation who are university professors with training in technologies and knowledge of how to apply technologies in a useful and effective way in companies, have a doctorate, and among their lines of research are technologies in companies. The experts questioned in this study are all teachers of business technology subjects in the areas of Business Administration, Organization and Management, with expertise in the use of these technologies from a business point of view, and have more than 10 years of teaching and research experience. These researchers all belong to different Spanish universities, and only one renowned researcher per university was interviewed.

- $\quad$ Professionals responsible for Information Technology (IT) in Spanish companies that have implemented IoT platforms in their companies, without taking into account the sector to which these companies belong (since this study is an analysis of the Spanish business sector in general) and without taking into account the size of these companies (since the study aims to make a generalized analysis, although most of the companies that have implemented these technologies in Spain can be considered large or medium-large companies, depending on their billing level and the number of their employees).

The opinion of both profiles received the same weight in the global adjacency matrix, since the opinion of both is equally important due to the two very different points of view that they contributed: one profile contributed the scientific-theoretical point of view in the implementation of this technology (in addition to their experience and knowledge in similar studies to the current one) and the other profile contributed a real-world point of view of the Spanish business sector when implementing this technology. The mean of both points of view was considered the most significant, since no great differences were found 
between the evaluations provided by the experts of the two types of profiles (this helped verify the significance of the results).

Regarding the number of participants in studies that use this type of methodology, this is determined by the appearance of new criteria in each of the interviews that are carried out; thus, the number of participants is considered optimal when the number of criteria involved stabilizes as interviews are conducted and when new criteria no longer appear as interviews are conducted [48]. This means that there are studies with this type of methodology with 45 [49], 41 [50], 40 [51], 29 [49], 8 [52-55], 7 [43], and 4 participants [56].

The number of participants in this study was set at 40 (20 researchers in technological implementation and 20 IT managers in Spanish companies), since none of the participants added new criteria in the interviews (Figure 1). This number of participants could have been lower, although it was decided to reach this number so that the results achieved would be the most significant possible.

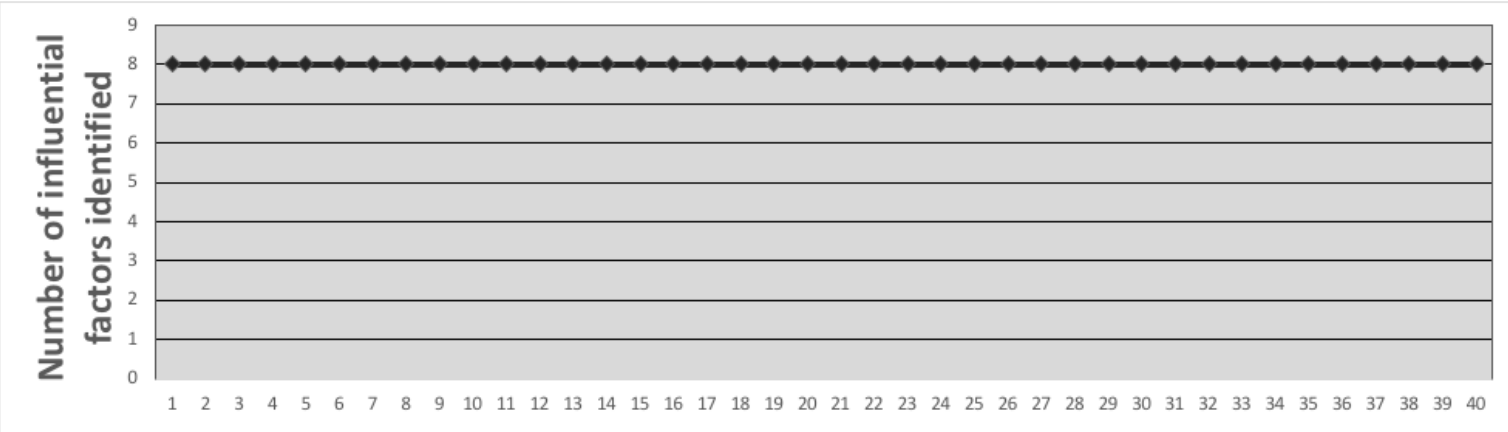

Number of interviewees

Figure 1. Number of criteria identified in each of the interviews.

\section{Results}

This section shows the results after applying the methodology of fuzzy cognitive maps and the subsequent use of the FCMappers software, showing (in the global adjacency matrix) the average valuations of the existing influences between each of these criteria and classifying the criteria by the degree of influence they exert on the other criteria, by the degree of influence they receive from the other criteria, and by the degree of participation or influence in the choice of IoT platforms in Spanish companies (which is calculated in each of the criteria as the sum of the degree of influence it exerts on the other criteria and the degree of influence it receives from the other criteria) [57].

\subsection{Global Adjacency Matrix}

As mentioned in the previous section, each interview generated an adjacency matrix with the information provided by each expert on the level of influence existing between the criteria and, subsequently, a global adjacency matrix was created with the average evaluations of these experts (obtaining the existence of 248 cause-effect relationships between the criteria involved in this decision) (Table 1).

This global adjacency matrix, reached with the use of the FCMappers software, allowed the criteria to be classified according to their level of importance in the choice of an IoT platform in companies, basing their level of importance on the degree of influence exerted and received among the criteria involved in this selection.

\subsection{Criteria Most Influencing Other Criteria}

After the analysis of the global adjacency matrix with the FCMappers software, it was identified that the criteria that most influence the rest of the criteria are (from greatest to least influence): previous experience, data ownership, stability, pricing model and business case, protocol, flexibility, interoperability, security, scalability, edge intelligence and control, 
system performance, data analytics and visualization tools, hybrid cloud, application environment, redundancy and disaster recovery, extent of legacy architecture, ownership of cloud infrastructure, bandwidth, attractive interface, platform migration, and time to market (Figure 2).

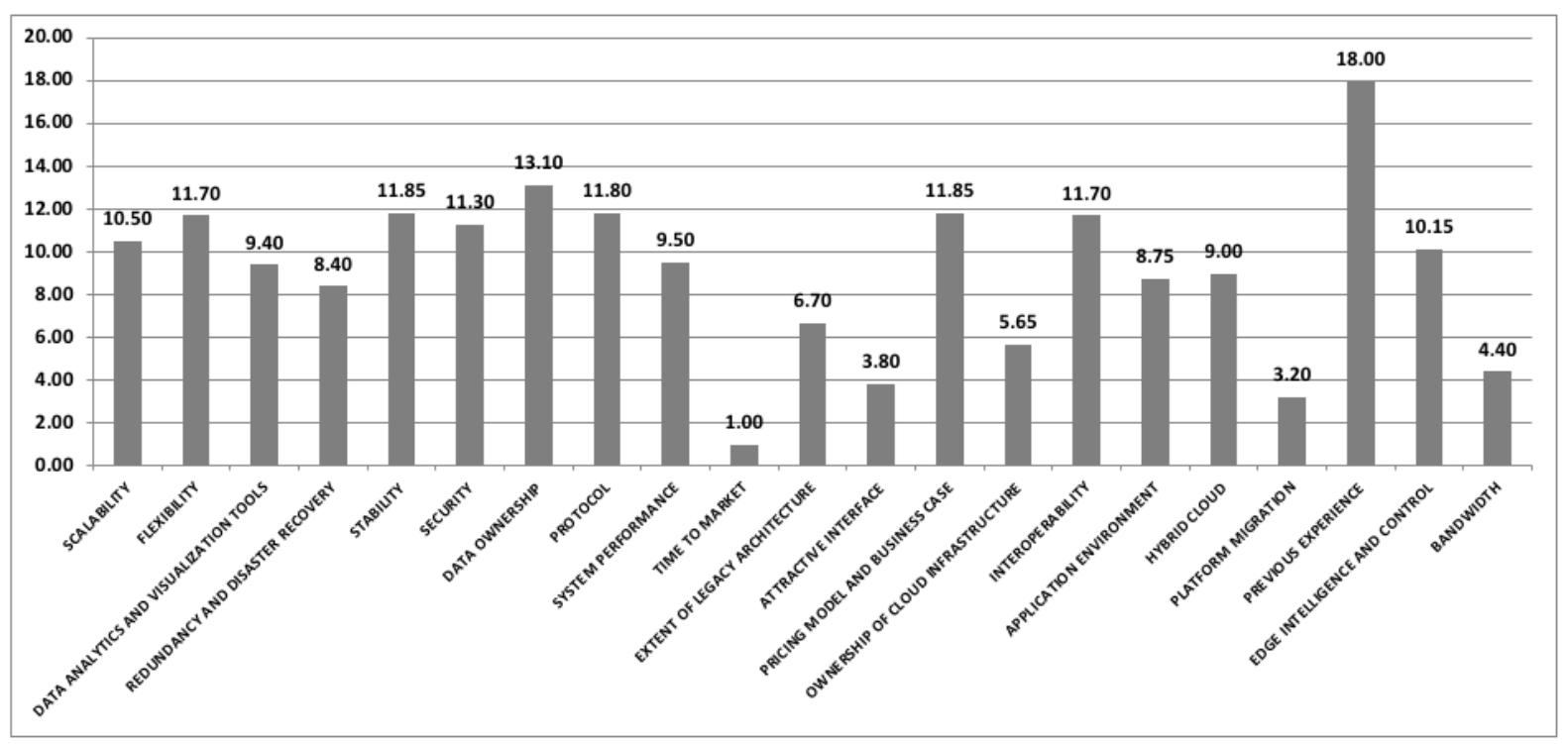

Figure 2. Criteria that most influence other criteria.

These evaluations were provided by the software based on the expert evaluations regarding the level of influence existing between the criteria involved in this choice. The criterion with the highest value is previous experience (18.00) and the criterion with the lowest value is time to market (1.00); between them, 10 criteria are equal to or above the average of these two criteria (9.50), and the other nine are below.

\subsection{Criteria That Receive the Most Influence from Other Criteria}

After the analysis of the global adjacency matrix with the FCMappers software, it was identified that the criteria that receive the most influence from other criteria are (from highest to least received influence): scalability, stability, security, flexibility, redundancy and disaster recovery, hybrid cloud, interoperability, pricing model and business case, extent of legacy architecture, data analytics and visualization tools, edge intelligence and control, application environment, ownership of cloud infrastructure, system performance, time to market, protocol, attractive interface, platform migration, bandwidth, data ownership, and previous experience (Figure 3).

These evaluations were provided by the software based on the expert evaluations regarding the level of influence existing between the criteria involved in this choice. The criterion with the highest value is scalability (18.60) and the criterion with the lowest value is previous experience (0.00); between them, 13 criteria are above the mean of these two criteria (9.30), and six are below. 


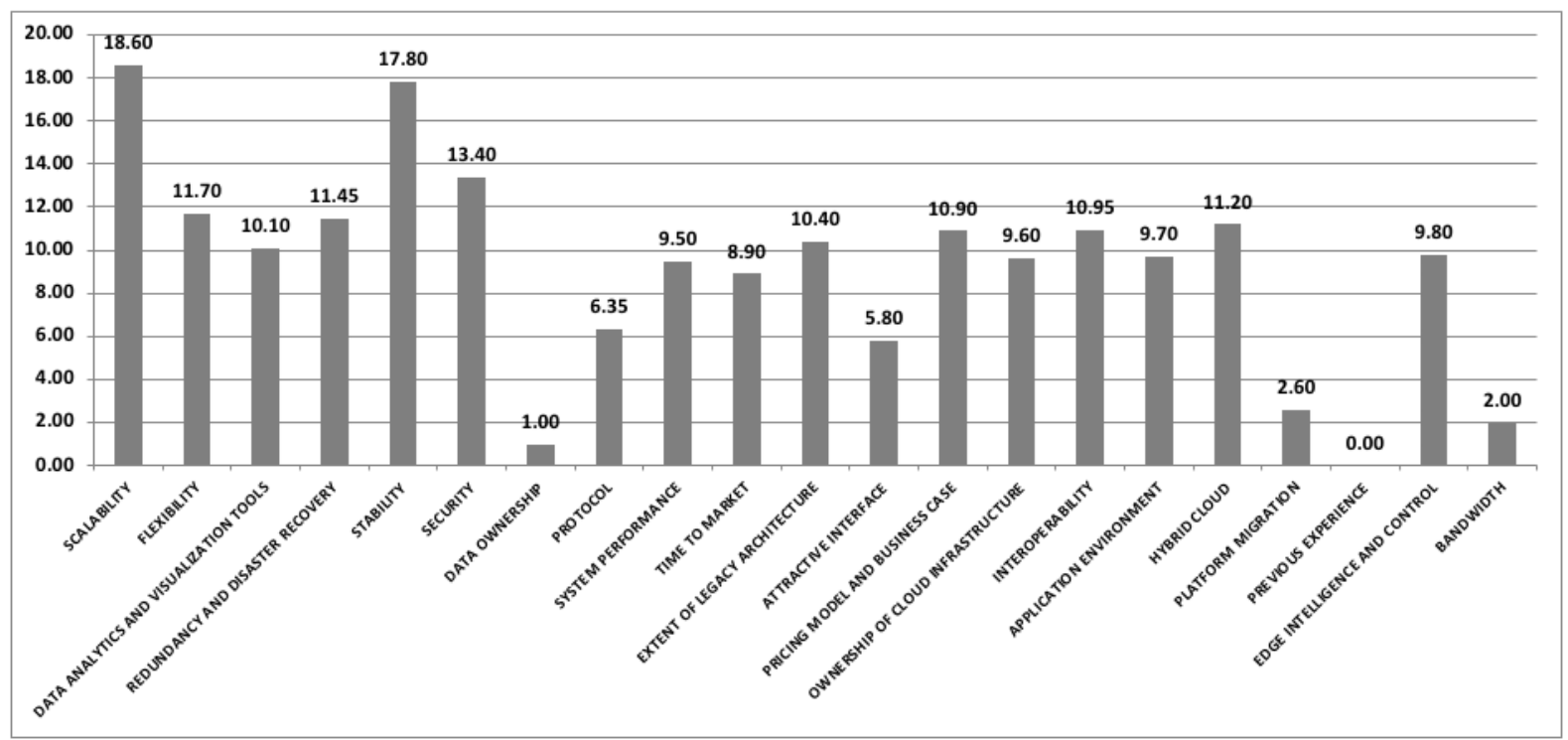

Figure 3. Criteria that receive the most influence from other criteria.

\subsection{Key Criteria in the Choice of IoT Platforms in Spanish Companies}

After the analysis of the global adjacency matrix with the FCMappers software, it was identified that the key criteria in the choice of IoT platforms in Spanish companies are (from highest to lowest importance): stability, scalability, security, flexibility, pricing model and business case, interoperability, hybrid cloud, edge intelligence and control, redundancy and disaster recovery, data analytics and visualization tools, system performance, application environment, protocol, previous experience, extent of legacy architecture, ownership of cloud infrastructure, data ownership, time to market, attractive interface, bandwidth, and platform migration (Figure 4).

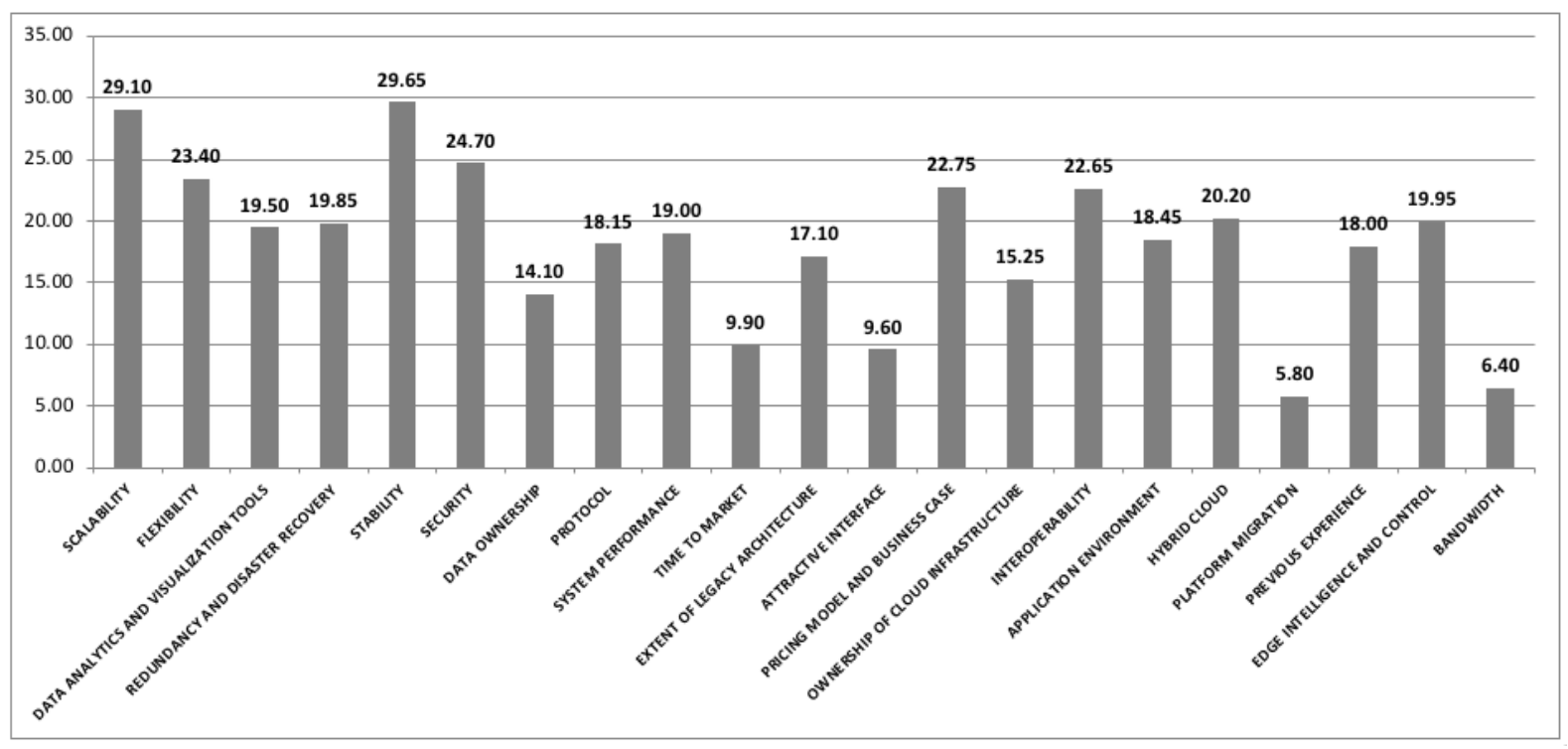

Figure 4. Key criteria in the choice of IoT platforms in Spanish companies.

As U. Özesmi and S. L. Özesmi [48] say, the key criteria in a decision are those that have the greatest degree of participation or influence in decision making. In this case, this degree of participation is determined by the influences exerted and the influences received.

Thus, this classification was obtained by the software based on the experts' evaluations. The criterion with the highest value is stability (29.65) and the criterion with the lowest 
value is platform migration (5.80); between them, 13 criteria are above the mean of these two criteria (17.725), and six are below.

\section{Discussion}

The business sector has previously gone through great revolutions caused by technological evolution and had to adapt to these revolutions in order to survive and to achieve new opportunities. Currently, a new revolution is taking place with the emergence of the IoT and its opportunities for use in companies, which affects the way in which data are collected and the way companies use and take advantage of these data.

This revolution can be observed in the global increase in companies that are beginning to use IoT in their operations and services [12], which is also reflected in the Spanish business sector [13].

However, although the level of implementation of this technology in Spanish companies is not low for a novel technology, it is true that there are a number of concerns expressed by this sector [12] that make its level of implementation not much higher. These concerns affect the choice of the IoT platform (the software necessary for the use of the IoT).

Today, the number of IoT platforms on the market is large and choosing one of them becomes a complicated process when a company decides to implement this technology. For this reason, this study located the criteria to be taken into account by Spanish companies when choosing an IoT platform (criteria that some platforms met and others did not) and classified them according to their level of importance in this decision (in order to know which of them companies should pay more attention to when choosing an IoT platform, since not all platforms comply with all criteria and this was a very difficult process for companies, which caused reluctance when implementing this technology).

Thus, at this point and by way of comparison and discussion of the results achieved in this study with respect to the results of other studies analyzed in the introduction and literature review sections, this section is developed based on the two hypotheses raised:

Hypothesis 1. The difficulties or concerns that Spanish companies encounter when betting on the implementation of the IoT are not the only criteria to take into account when choosing an IoT platform.

The difficulties or concerns that Spanish companies encounter when betting on the implementation of the IoT are the initial costs, security, and privacy [12], but these should not be the only criteria to be taken into account by Spanish companies in the choice of the IoT platform.

This was already analyzed in the study by Ullah, Nardelli, Wolff, and Smolander [16] for companies in general worldwide, where 21 criteria were found: scalability, flexibility, data analytics and visualization tools, redundancy and disaster recovery, stability, security, data ownership, protocol, system performance, time to market, extent of legacy architecture, attractive interface, pricing model and business case, ownership of cloud infrastructure, interoperability, application environment, hybrid cloud, platform migration, previous experience, edge intelligence and control, and bandwidth.

In this study, all these criteria were ratified by the experts interviewed as the criteria to be taken into account by Spanish companies when choosing an IoT platform.

Before these two studies, as can be seen in the literary review, there was research that involved the participation of some of these criteria in this decision, but none grouped all the criteria.

Hypothesis 2. The difficulties or concerns that Spanish companies encounter when betting on the implementation of the IoT are not the most relevant criteria or key criteria in the choice of IoT platforms, since there are other criteria to take into account when choosing IoT platforms with equal or greater importance. 
The existing research on this problem discussed in the literary review reflects that these investigations tried to find out key criteria by independently assessing the degree of influence of each of these criteria on this decision and without taking into account all of these criteria and that the criteria that influence this decision influence each other, which can cause changes in the relevance of each of these in decision making [47]. An example of this can be seen in the study by Gallego Gómez [12], a study focused on the field of Spanish companies and the problems studied here.

This has been taken into account in this study, meaning that criteria that do not seem relevant or worrying at first to Spanish companies could be and should be taken into account in this choice. Thus, the classification of the criteria according to the level of importance when choosing an IoT platform would be (from highest to lowest importance): stability, scalability, security, flexibility, pricing model and business case, interoperability, hybrid cloud, edge intelligence and control, redundancy and disaster recovery, data analytics and visualization tools, system performance, application environment, protocol, previous experience, extent of legacy architecture, ownership of cloud infrastructure, data ownership, time to market, attractive interface, bandwidth, and platform migration.

With this classification, it was observed that two of the six most important criteria in this decision coincided with the main concerns of Spanish companies when implementing this technology (initial costs, security, and privacy [12]), in addition to criteria that initially did not stand out as being key criteria. This was due to the fact that the methodology used in this study (fuzzy cognitive maps) takes into account that the criteria that influence a decision influence each other [47].

In this way, the additional criteria that became key criteria in this selection (and that were not considered as key before) are stability, scalability, flexibility, and interoperability (which were added to the security and pricing model and business case, which were those that directly implied the main concerns of the companies: initial costs, security, and privacy); they directly and indirectly influence the main concerns of Spanish companies when implementing this technology, to such a level that their importance is higher than that for some criteria directly implied by the main concerns of companies (security and pricing model and business case).

\section{Conclusions}

With all this, this study glimpsed what criteria should be taken into account by Spanish companies when choosing an IoT platform (scalability, flexibility, data analytics and visualization tools, redundancy and disaster recovery, stability, security, data ownership, protocol, system performance, time to market, extent of legacy architecture, attractive interface, pricing model and business case, ownership of cloud infrastructure, interoperability, application environment, hybrid cloud, platform migration, previous experience, edge intelligence and control, and bandwidth), and identified the key criteria in choosing one platform over another (stability, scalability, security, flexibility, pricing model and business case, and interoperability). This evidenced that there were key criteria beyond the criteria directly implied by the concerns of Spanish companies when implementing this technology, such as the stability, scalability, flexibility, and interoperability criteria, which have the same or greater importance.

This was due to the fact that this study took into account that the criteria that influence a decision influence each other, and this could give rise to criteria not being considered at first, even though they should be taken into account in this choice. The existing studies on this problem did not consider this.

In this way, the true key criteria relevant to the choice of one or another IoT platform were revealed, in order to facilitate this process for Spanish companies that want to implement this technology in the future, and in order to encourage other companies that did not have plans to implement this technology because they encountered too much difficulty in this process to do so. 
The incorporation of this technology into companies will generate great value in these, thanks to the data that it can collect and the use of that data. This value is seen in the benefits it brings to companies: savings in energy consumption, reduction in costs due to failures in machinery and production lines, greater production efficiency, better use of changing markets, greater understanding of their customers, better service to their clients, greater security for their employees, greater security and privacy of company information, and better decision making and strategy planning, among others.

This research was limited to the study of key criteria in the choice of IoT platforms in Spanish companies, since the main concerns of Spanish companies when implementing this technology have been identified (through previous studies). However, this territorial limitation could be eliminated in future research by identifying whether these concerns are the same in other territories or not, and if this is not the case, carrying out this same study in the territory of the companies to be analyzed, with experts in technological implementation and professionals responsible for information technology in companies in that territory. Further progress could be made in the studies level of detail if the analyses were made based on the size of the company, if a considerable number of companies of various sizes were included.

Author Contributions: Conceptualization, methodology, software, formal analysis, investigation, resources, data curation, writing - original draft preparation, validation, writing-review and editing, visualization, supervision, and project administration, A.I.-M., J.C.I.-M., J.G.-P. and F.J.M.-L. All authors have read and agreed to the published version of the manuscript.

Funding: This research received no external funding.

Institutional Review Board Statement: Not applicable.

Informed Consent Statement: Not applicable.

Data Availability Statement: Not applicable.

Conflicts of Interest: The authors declare no conflict of interest.

\section{References}

1. Alvarado, J. The Real Impact of IoT on Businesses. Available online: https://sg.com.mx/revista/51/el-impacto-real-del-iot-lasempresas (accessed on 15 July 2021). (In Spanish)

2. Infante-Moro, A.; Infante-Moro, J.C.; Gallardo-Pérez, J. Analysis of digital competences in the Master of Tourism of the University of Huelva [Análisis de las competencias digitales en el Máster de Turismo de la Universidad de Huelva]. Campus Virtuales 2021, 10, 141-151.

3. Rodríguez-Abitia, G.; Ramírez-Montoya, M.S.; López-Caudana, E.O.; Romero-Rodríguez, J.M. Factors for the development of computational thinking in undergraduate students [Factores para el desarrollo del pensamiento computacional en estudiantes de pregrado]. Campus Virtuales 2021, 10, 153-164.

4. Holgado, A.G.; Ingelmo, A.V.; Peñalvo, F.J.G.; Conde, M.J.R. Improvement of Learning Outcomes in Software Engineering: Active Methodologies Supported Through the Virtual Campus. Rev. Iberoam. Tecnol. Aprendiz. 2021, 16, 143-153. [CrossRef]

5. Grande de Prado, M.; García Peñalvo, F.J; Corell, A.; Abella-García, V. Higher Education assessment during COVID-19 pandemic [Evaluación en Educación Superior durante la pandemia de la COVID-19]. Campus Virtuales 2021, 10, 49-58.

6. Dospinescu, O.; Dospinescu, N. The use of information technology toward the ethics of food safety. Ecoforum J. 2018, 7, 1-11.

7. Adecco Institute. 10 Benefits of IoT for Companies. Available online: https://www.adeccoinstitute.es/futuro-del-trabajo-ytecnologia/10-beneficios-del-iot-para-empresas (accessed on 15 July 2021). (In Spanish)

8. Infante-Moro, A.; Infante-Moro, J.C.; Gallardo-Pérez, J. Key Factors in the Implementation of the Internet of Things in the Hotel Sector. Appl. Sci. 2021, 11, 2924. [CrossRef]

9. Infante-Moro, A.; Infante-Moro, J.C.; Gallardo-Pérez, J. Factors that influence the adoption of the Internet of Things in the hotel sector [Factores que influyen en la adopción del Internet de las Cosas en el sector hotelero]. RISTI-Rev. Iber. Sist. Tecnol. Inf. 2021, 41, 370-383.

10. Infante-Moro, A.; Infante-Moro, J.C.; Gallardo-Pérez, J. Motivational factors that justify the implementation of the Internet of Things as a security system in the hotel sector [Factores motivacionales que justifican la implementación del Internet de las Cosas como sistema de seguridad en el sector hotelero]. Rev. Pensam. Estratégico Segur. CISDE 2020, 5, 81-91.

11. Infante-Moro, A.; Infante-Moro, J.C.; Gallardo-Pérez, J. The employment possibilities of the internet of things in the hotel sector and its training needs [Las posibilidades de empleo del Internet de las Cosas en el sector hotelero y sus necesidades formativas]. Educ. Knowl. Soc. 2020, 21, 14. [CrossRef] 
12. Gallego Gómez, C. Internet of Things. International Comparison, Spain and Autonomous Communities. Available online: http:/ / marketing.eae.es/prensa/SRC_loT.pdf (accessed on 15 July 2021). (In Spanish)

13. INE. Percentage of Companies That Used Interconnected Devices That Can Be Remotely Monitored or Controlled through the Internet (IoT). Survey on the Use of ICT and Electronic Commerce in Companies. Available online: https://www.ine.es/jaxi/ Datos.htm?tpx=37754 (accessed on 21 July 2021). (In Spanish)

14. BarbaraIoT. IoT Platforms: What They Are and How They Can Benefit Your Company. Available online: https://barbaraiot.com/ blog/plataformas-iot-que-son-y-como-pueden-beneficiar-a-tu-empresa (accessed on 21 July 2021). (In Spanish)

15. Fernández, R. Number of Internet of Things Platforms Globally from 2015 to 2019. Available online: https: / / es.statista.com/ estadisticas /1117936/plataformas-de-internet-de-las-cosas-a-nivel-mundial (accessed on 21 July 2021). (In Spanish)

16. Ullah, M.; Nardelli, P.H.; Wolff, A.; Smolander, K. Twenty-one key factors to choose an iot platform: Theoretical framework and its applications. IEEE Internet Things J. 2020, 7, 10111-10119. [CrossRef]

17. Hejazi, H.; Rajab, H.; Cinkler, T.; Lengyel, L. Survey of platforms for massive IoT. In Proceedings of the IEEE International Conference on Future IoT Technologies (Future IoT), Eger, Hungary, 18-19 January 2018; pp. 1-8. [CrossRef]

18. Gigli, M.; Koo, S. Internet of Things: Services and applications categorization. Adv. Internet Things 2011, 1, 27-31. [CrossRef]

19. IOTIFY. Top 10 Criteria to Choose the Best IoT Cloud Platform. Available online: http:/ /iot.microprocessadores.com.br/Top1 0criteria_.pdf (accessed on 22 July 2021).

20. McClelland, C. How to Choose the Best IoT Platform. Available online: https://www.leverege.com/blogpost/how-to-choosethe-best-iot-platform (accessed on 22 July 2021).

21. Khakurel, J. Enhancing the Adoption of Quantified Self-Tracking Devices. Available online: http://urn.fi/URN:ISBN:978-952-33 5-319-0 (accessed on 22 July 2021).

22. Salman, T. Internet of Things Protocols and Standards. Available online: https://www.cse.wustl.edu/ \{\}jain/cse570-15/ftp/iot_ prot (accessed on 22 July 2021).

23. Vandikas, K.; Tsiatsis, V. Performance evaluation of an IoT platform. In Proceedings of the 8th International Conference on Next Generation Mobile Apps, Services and Technologies, Oxford, UK, 10-12 September 2014; pp. 141-146. [CrossRef]

24. Matthew, J.P. Evaluating and Choosing an IoT Platform. Available online: https://www.oreilly.com/learning/evaluatingchoosing-iot-platform (accessed on 22 July 2021).

25. Hayretci, H.E.; Aydemir, F.B. A Multi Case Study on Legacy System Migration in the Banking Industry. In Advanced Information Systems Engineering. CAiSE 2021. Lecture Notes in Computer Science; La Rosa, M., Sadiq, S., Teniente, E., Eds.; Springer: Cham, Switzerland, 2021; Volume 12751, pp. 536-550. [CrossRef]

26. Dospinescu, O.; Perca, M. Web Services in Mobile Applications. Inform. Econ. 2013, 17, 17-26. [CrossRef]

27. DeviceHive. How to Choose Your IoT Platform-Should You Go Open-Source? Available online: https://medium.com/iotforall/ how-to-choose-your-iot-platform-should-you-go-open-source-23148a0809f3 (accessed on 22 July 2021).

28. Lamarre, E.; May, B. Making Sense of Internet of Things Platforms. Available online: https://www.mckinsey.com/businessfunctions / mckinsey-digital/our-insights/making-sense-of-internet-of-things-platforms (accessed on 22 July 2021).

29. Kooand, J.; Kim, Y. Interoperability of device identification in heterogeneous IoT platforms. In Proceedings of the 13th International Computer Engineering Conference (ICENCO), Cairo, Egypt, 27-28 December 2017; pp. 26-29. [CrossRef]

30. Xiao, G.; Guo, J.; Xu, L.D.; Gong, Z. User interoperability with heterogeneous IoT devices through tIansformation. IEEE Trans. Ind. Inform. 2014, 10, 1486-1496. [CrossRef]

31. Rantos, K.; Spyros, A.; Papanikolaou, A.; Kritsas, A.; Ilioudis, C.; Katos, V. Interoperability Challenges in the Cybersecurity Information Sharing Ecosystem. Computers 2020, 9, 18. [CrossRef]

32. Dospinescu, O.; Strîmbei, C.; Strainu, R.M.; Nistor, A. REST SOA Orchestration and BPM Platforms. Inform. Econ. 2017, 21, 30-42. [CrossRef]

33. Lee, I. Pricing and Profit Management Models for SaaS Providers and IaaS Providers. J. Theor. Appl. Electron. Commer. Res. 2021, 16, 859-873. [CrossRef]

34. Lula, P.; Dospinescu, O.; Homocianu, D.; Sireteanu, N.A. An advanced analysis of cloud computing concepts based on the computer science ontology. Comput. Mater. Contin. 2021, 66, 2425-2443. [CrossRef]

35. Loghin, D.; Ramapantulu, L.; Teo, Y.M. On understanding time, energy and cost performance of Wimpy heterogeneous systems for edge computing. In Proceedings of the IEEE 1st International Conference on Edge Computing (EDGE), Honolulu, HI, USA, 25-30 June 2017; pp. 1-8. [CrossRef]

36. Lee, J. The 6 Complexities of Building a Managed IoT Platform. Available online: https://hackernoon.com/the-6-complexitiesof-hosting-a-managed-iot-service-b7696eea52ba (accessed on 22 July 2021).

37. Al-Zihad, M.; Akash, S.A.; Adhikary, T.; Razzaque, M.A. Bandwidth allocation and computation offloading for service specific IoT edge devices. In Proceedings of the 5th IEEE Region 10 Humanitarian Technology Conference, Dhaka, Bangladesh, 21-23 December 2018; pp. 516-519. [CrossRef]

38. Papageorgiou, E.I.; Salmerón, J.L. A Review of Fuzzy Cognitive Maps Research During the Last Decade. IEEE Trans. Fuzzy Syst. 2013, 21, 66-79. [CrossRef]

39. Maridueña, M.R.; Leyva, M.; Febles, A. Modeling and analysis of science and technology indicators using fuzzy cognitive maps [Modelado y análisis de indicadores de ciencia y tecnología mediante mapas cognitivos difusos]. Cienc. Inf. 2016, 47, 17-24. 
40. Papageorgiou, E.I.; Markinos, A.T.; Gemtos, T. Application of fuzzy cognitive maps for cotton yield management in precision farming. Expert Syst. Appl. 2009, 36, 12399-12413. [CrossRef]

41. Curia, L.; Lavalle, A. Decision strategies in dynamic systems-applying fuzzy cognitive maps application to a socio-economic example [Estrategias de decisión en sistemas dinámicos-aplicando mapas cognitivos difusos aplicación a un ejemplo socioeconómico]. J. Inf. Syst. Technol. Manag. 2011, 8, 663-680. [CrossRef]

42. Codara, L. Le Mappe Cognitive; Carocci Editore: Rome, Italy, 1998.

43. Solana Gutierrez, J.; Rincón Sanz, G.; Alonso González, C.; Garcia De Jalon Lastra, D. Use of Maps of Diffuse Knowledge (FCMs) in the prioritization of river restoration: Application to the Esla River [Utilización de Mapas de Conocimiento Difuso (MCD) en la asignación de prioridades de la restauración fluvial: Aplicación al río Esla]. Cuad. Soc. Española Cienc. For. 2015, 41, 367-380.

44. Mouratiadou, I.; Moran, D. Mapping public participation in the Water Framework Directive: A case study of the Pinios River Basin, Greece. Ecol. Econ. 2007, 62, 66-76. [CrossRef]

45. Banini, G.A.; Bearman, R.A. Application of fuzzy cognitive maps to factors affecting slurry rheology. Int. J. Miner. Process. 1998, 52, 233-244. [CrossRef]

46. Bachhofer, M.; Wildenberg, M. FCMappers. Available online: http:/ /www.fcmappers.net (accessed on 24 July 2021).

47. Infante-Moro, A.; Infante-Moro, J.C.; Gallardo-Pérez, J. Fuzzy Cognitive Maps and their application in social science research: A study of their main problems [Los mapas cognitivos difusos y su aplicación en la investigación de las ciencias sociales: Estudio de sus principales problemáticas]. Educ. Knowl. Soc. 2021, 22, e26380. [CrossRef]

48. Özesmi, U.; Özesmi, S.L. Ecological models based on people's knowledge: A multistep Fuzzy Cognitive Mapping approach. Ecol. Model. 2004, 176, 43-64. [CrossRef]

49. Carley, K.; Palmquist, M. Extracting, representing, and analyzing mental models. Soc. Forces 1992, 70, 601-636. [CrossRef]

50. Infante Moro, J.C. User Perception to Improve the Use of Social Networks as a Communication Channel in the Hotel Sector [Percepción de los Usuarios Para la Mejora del uso de las Redes Sociales Como Canal de Comunicación en el Sector Hotelero]. Ph.D. Thesis, University of Huelva, Huelva, Spain, 2017.

51. Infante-Moro, A.; Infante-Moro, J.C.; Gallardo-Pérez, J.; Luque-de la Rosa, A. Motivational Factors in the Use of Videoconferences to Carry out Tutorials in Spanish Universities in the Post-Pandemic Period. Int. J. Environ. Res. Public Health 2021, 18,10474 [CrossRef]

52. González-González, C.S.; Infante-Moro, A.; Infante-Moro, J.C. Implementation of E-proctoring in Online Teaching: A Study About Motivational Factors. Sustainability 2020, 12, 3488. [CrossRef]

53. Infante-Moro, A.; Infante-Moro, J.C.; Gallardo-Pérez, J. Motivational factors in the insertion of digital skills in teaching. In Eighth International Conference on Technological Ecosystems for Enhancing Multiculturality; Association for Computing Machinery: New York, NY, USA, 2020; pp. 365-370. [CrossRef]

54. Infante-Moro, A.; Infante-Moro, J.C.; Gallardo-Pérez, J. Key factors in the implementation of Cloud Computing as a service and communication tool in universities. In Proceedings of the Eighth International Conference on Technological Ecosystems for Enhancing Multiculturality, Salamanca, Spain, 21-23 October 2020; pp. 631-636. [CrossRef]

55. Infante-Moro, A.; Infante-Moro, J.C.; Gallardo-Pérez, J.; Salgado Ferreira, L. Motivational factors in the insertion of Cloud Computing in teaching. In Proceedings of the 10th International Conference on Virtual Campus, JICV 2020, Tetouan, Morocco, 3-5 December 2020; pp. 1-5. [CrossRef]

56. Amat Abreu, M.; Ortega Tenezaca, D.B.; Yaguar Mariño, J.J. Determination of the degree of influence of the climatic factors of vulnerability of the agricultural sector with neutrosophic techniques [Determinación del grado de influencia de los factores climáticos de vulnerabilidad del sector agropecuario con técnicas neutrosóficas]. Investig. Oper. 2020, 41, 699-705.

57. Özesmi, U.; Özesmi, S.L. A participatory approach to ecosystem conservation: Fuzzy cognitive maps and stakeholder group analysis in Uluabat Lake, Turkey. Environ. Manag. 2003, 31, 0518-0531. [CrossRef] [PubMed] 